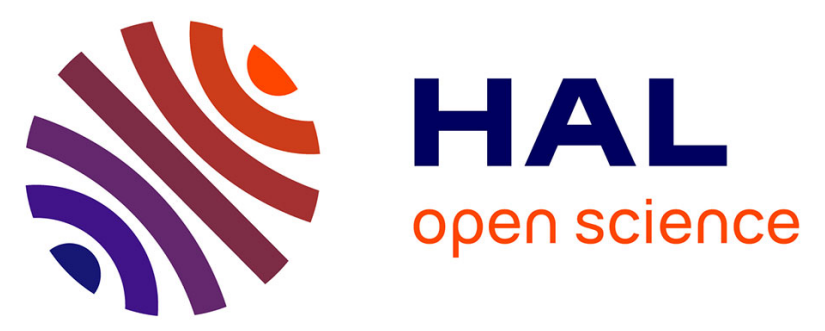

\title{
Surface Plasmon Resonance Imaging-Mass Spectrometry Coupling on Antibody Array Biochip: Multiplex Monitoring of Biomolecular Interactions and On-Chip Identification of Captured Antigen
}

\author{
Anastasiia Halushkina, William Buchmann, Nathalie Jarroux, Régis Daniel
}

\section{To cite this version:}

Anastasiia Halushkina, William Buchmann, Nathalie Jarroux, Régis Daniel. Surface Plasmon Resonance Imaging-Mass Spectrometry Coupling on Antibody Array Biochip: Multiplex Monitoring of Biomolecular Interactions and On-Chip Identification of Captured Antigen. Whittaker, Kelly C., Huang, Ruo-Pan. Antibody Arrays, Methods and Protocols, Springer US, pp.55-67, 2020, Antibody Arrays, 978-1-0716-1063-3. 10.1007/978-1-0716-1064-0_5 . hal-03098106

\section{HAL Id: hal-03098106 \\ https: / hal-univ-evry.archives-ouvertes.fr/hal-03098106}

Submitted on 26 Nov 2021

HAL is a multi-disciplinary open access archive for the deposit and dissemination of scientific research documents, whether they are published or not. The documents may come from teaching and research institutions in France or abroad, or from public or private research centers.
L'archive ouverte pluridisciplinaire HAL, est destinée au dépôt et à la diffusion de documents scientifiques de niveau recherche, publiés ou non, émanant des établissements d'enseignement et de recherche français ou étrangers, des laboratoires publics ou privés. 


\section{Surface Plasmon Resonance Imaging-} Mass Spectrometry Coupling on Antibody Array Biochip: Multiplex Monitoring of Biomolecular Interactions and On-Chip Identification of Captured Antigen

Anastasiia Halushkina 1

William Buchmann 1

Nathalie Jarroux 1

Régis Daniel 2ه

Email regis.daniel@univ-evry.fr

1 Université Evry Paris-Saclay AQ1 , Évry, Essonne, France

2 CNRS UMR 8587, LAMBE, University of Evry Val d'Essonne, Évry, France

\section{Abstract}

The coupling of surface plasmon resonance imaging (SPRi) with mass spectrometry (MS) offers a very promising multidimensional analysis. This system takes advantage of the two well-established techniques: SPR, which allows for the analysis of biomolecular interactions through the determination of kinetic and thermodynamic constants, and MS, which can characterize biological structures from mass measurements and fragmentation experiments. Here, a protocol for the coupling of SPRi with matrix-assisted laser desorption/ionization mass spectrometry (MALDI-MS) is described using a biochip grafted by antibodies in an array format. Interaction between $\beta$-lactoglobulin antibodies and the protein antigen is detected and analyzed by SPRi. Then, the arrayed 
biochip which fitted a commercially MALDI target was inserted in a MALDI source, and mass spectra were recorded directly from the biochip surface from each antibody spot, showing protein ions attributed to the corresponding specific protein antigens.

\section{Key words}

Biomolecular interactions

Surface plasmon resonance

Mass spectrometry

Matrix-assisted laser desorption/ionization

Poly(ethylene glycol)

$\beta$-Lactoglobulin

Antibodies

\section{Introduction}

Biomolecular interactions are at the core of numerous biological processes, and several techniques are available to determine either their thermodynamic features or their structural determinants. The hyphenation of thermodynamic and structural methods raises much interest as it allows a multidimensional and comprehensive characterization of biointeractions. The coupling of surface plasmon resonance (SPR) with mass spectrometry (MS) from a unique surface common to both techniques, socalled SPR-MS coupling, meets this objective of full characterization as SPR provides kinetic and thermodynamic data by real-time monitoring of bio-interactions $[1,2,3,4,5,6]$ and MS allows the structural identification of the specifically captured ligands on the SPR sensor surface $[7,8,9]$. The SPR monitoring of bio-interactions requires the immobilization of one partner of interaction (i.e., receptor) on a biosensor surface or in a channel, whereas potential binding partners (ligands) are flowed over the immobilized receptors. Because SPR does not provide any structural data about the captured ligands due to the principle of SPR detection based on optical measurement, the coupling with MS provides a real added value in this respect [10].

Initial SPR-MS developments were based on the use of a sensor chip with a limited number of flow cells, requiring elution steps for the recovery of the captured biomolecules and their subsequent MS analysis [11, 12, 13, 
$14,15,16]$. Alternatively, a SPR-MS coupling based on a sensor chip in a microarray format has been developed in the past decade, allowing multiplexed and high-throughput SPR-MS analyses involving SPR imaging (SPRi) and matrix-assisted laser desorption/ionization (MALDI)MS on the same sensor surface $[17,18,19,20,21,22]$. This chapter will describe a step-by-step procedure to implement this recently developed SPRi-MALDI-MS method, including (1) the SPRi biochip preparation, (2) the SPRi experiment allowing the determination of interaction and the ligand capture, and (3) the direct on-chip MALDI-MS detection of specifically retained ligands (Fig. 1). More precisely, the procedure will be applied to the analysis of antibody-antigen interactions as an example. We will detail in a first step the functionalization of the chip gold surface by a self-assembled monolayer (SAM) of short poly(ethylene glycol) (PEG) chains, a key step in order to reduce the nonspecific binding, especially when analyzing bio-interactions in complex mixtures such as in biological fluids. The PEG chains are terminated by a $N$-hydroxysuccinimide (NHS) group as an active end for antibody grafting. Then, we will describe the SPRi detection and recording of the complex formation between $\beta$-lactoglobulin and its corresponding antibody immobilized on the sensor surface over a range of concentrations $(1-100 \mu \mathrm{g} / \mathrm{mL} \sim 54.5 \mathrm{nM}-5.45 \mu \mathrm{M})$ (Fig. 2a). Last, we will describe the MALDI-MS detection and identification of the specifically retained antigen on the receptor spots directly from the biochip surface. Femtomolar amounts of captured $\beta$-lactoglobulin, as determined by SPR, were sufficient for the on-chip direct MS detection and to obtain good quality mass spectra. The mass spectra exhibited protein ions corresponding to the specific antigen, without any trace of nonspecific ligand (Fig. 2b). The biochip surface free from receptors was also devoid of nonspecifically bound proteins (Fig. 2c), indicating that the functionalization of the sensor surface by short PEG chains greatly minimizes the unspecific binding.

\section{Fig. 1}

Main steps of the SPRi-MALDI-MS experiment: (1) SPRi biochip preparation, (2) SPRi experiment allowing the determination of interaction and ligand capture, and (3) direct on-chip MALDI-MS detection of specifically retained ligands 


\section{(1) SPRi biochip preparation}

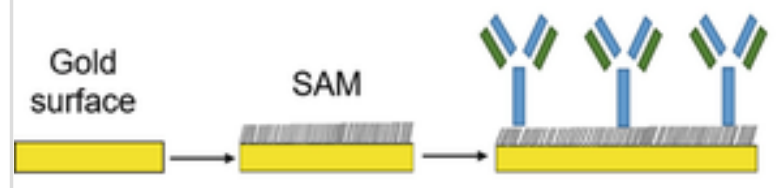

(2) SPRi Experiment
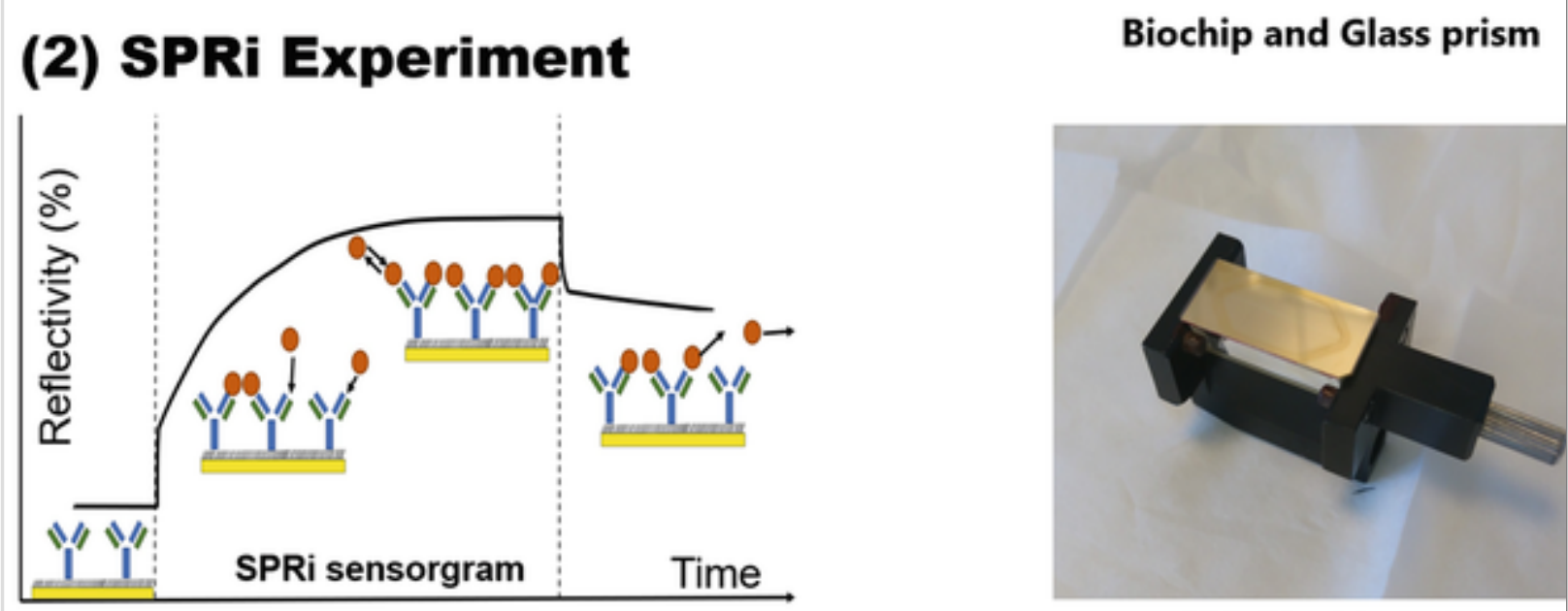

SPR Biochip holder

\section{(3) MALDI-TOF analysis}

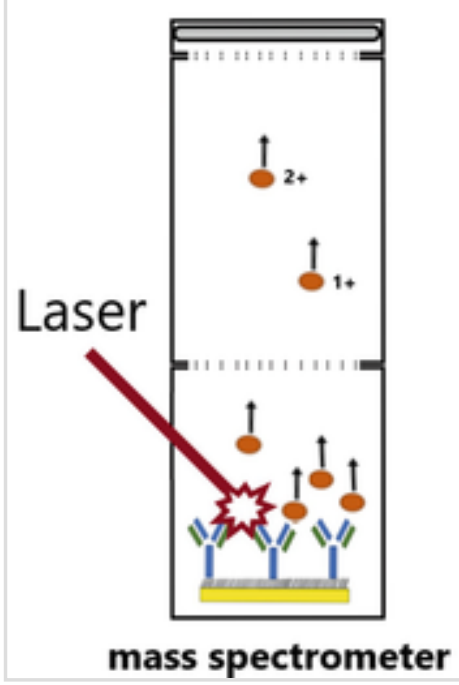

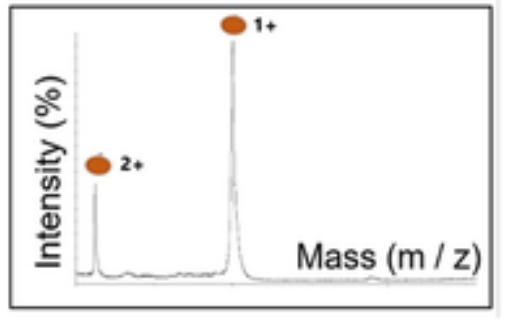

mass spectrum

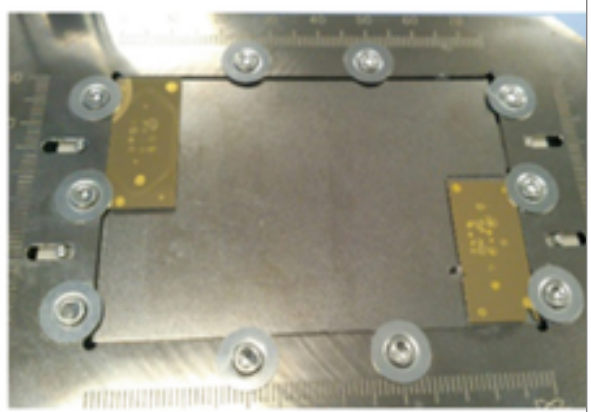

MALDI plate with 2 biochip:

Fig. 2

(a) SPRi sensorgrams obtained after injections of $\beta$-lactoglobulin at different concentrations $(1,10$, and $100 \mu \mathrm{g} / \mathrm{mL})$ in $10 \mathrm{mM}$ ammonium acetate buffer $\mathrm{pH}$ 7.5, (b) MALDI-TOF mass spectrum obtained after the SPRi experiment directly from an anti- $\beta$-lactoglobulin antibody plot of biochip surface, (c) MALDI-TOF mass spectrum obtained after the SPRi experiment directly from a passivated area of the biochip surface

AQ2 


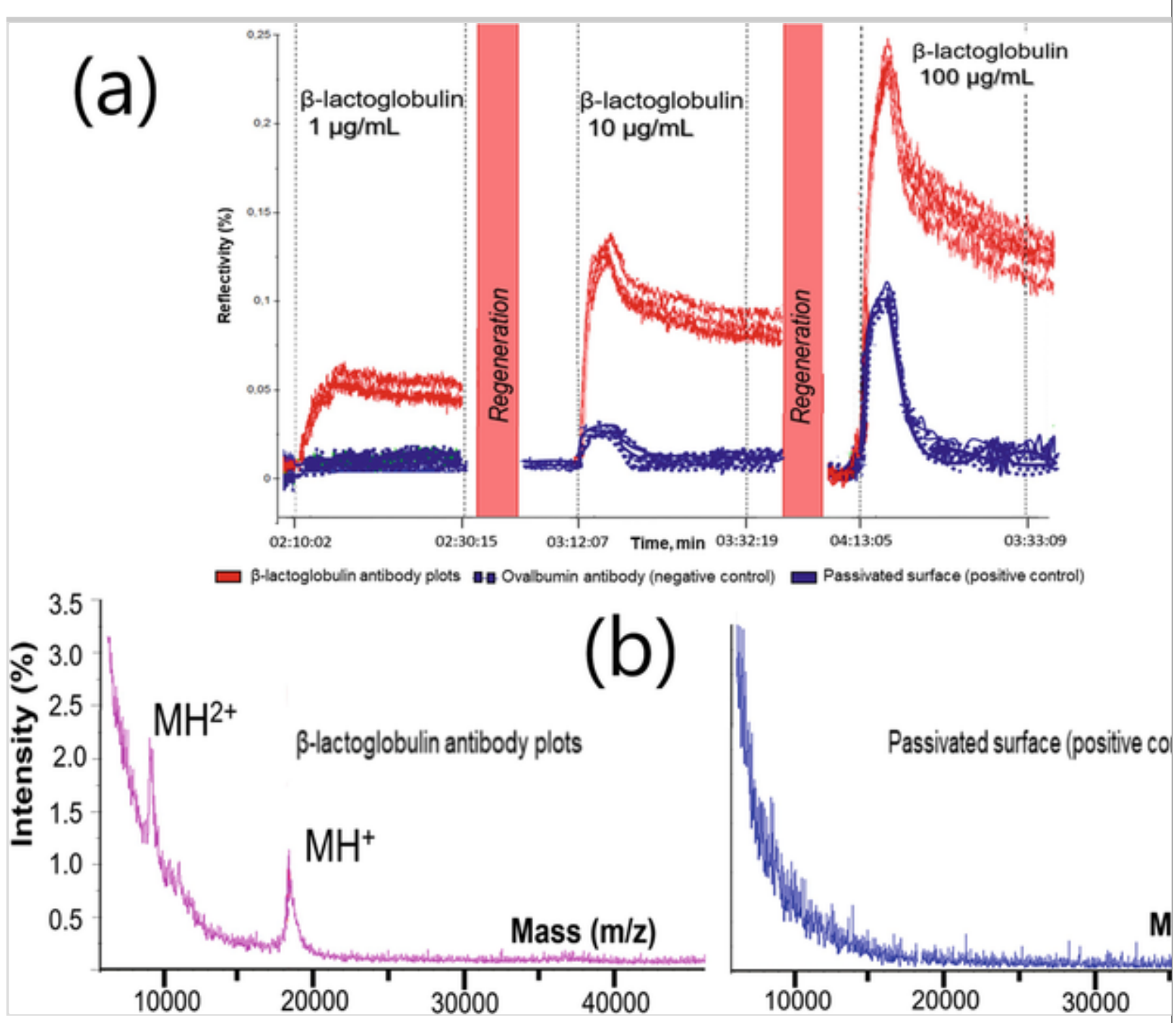

\section{Materials}

\subsection{Chemical Reagents}

1. $O$-(2-Carboxyethyl)- $O^{\prime}$-(mercaptoethyl)-heptaethylene glycol (PEG) aliquoted to $3.5 \mu \mathrm{L}(\sim 4 \mathrm{mg})$ and stored at $-20^{\circ} \mathrm{C}$.

2. 4-Pyrrolidinopyridine.

3. N-Hydroxysuccinimide (NHS).

4. $N, N^{\prime}$-Dicyclohexylcarbodiimide (DCC).

5. 2-(4-Hydroxyphenylazo)-benzoic acid (HABA, MALDI matrix).

6. Trifluoroacetic acid (TFA). 
7. High index liquid "Serie B" for connection between glass prism and SPRi-Slides (HORIBA Scientific, France).

8. $55 \%(\mathrm{v} / \mathrm{v})$ Glycerol prepared by dilution in deionized water from $100 \%$ glycerol.

\subsection{Proteins (Receptors and Ligands)}

Protein solutions can be prepared and stored up to 1 week, at $4{ }^{\circ} \mathrm{C}$ (unless indicated otherwise).

1. $\beta$-Lactoglobulin from bovine milk.

2. Polyclonal antibody against $\beta$-lactoglobulin.

3. Monoclonal antibody against ovalbumin.

\subsection{Solvents, Buffer, and Solutions for SPRi Experiment}

All aqueous solutions should be prepared using ultrapure water and analytical grade reagents.

1. Ultrapure water, $18.2 \mathrm{M} \Omega \mathrm{cm}$.

2. Ethanol absolute.

3. Dimethyl sulfoxide (DMSO).

4. Current buffer for SPRi: $10 \mathrm{mM}$ ammonium acetate, $\mathrm{pH}$ 7.5. Add about $500 \mathrm{~mL}$ water to a $1 \mathrm{~L}$ graduated cylinder or a glass beaker, and transfer $1.33 \mathrm{~mL}$ of $7.5 \mathrm{M}$ ammonium acetate stock solution to the cylinder as well. Add water to a volume of $900 \mathrm{~mL}$. Mix and adjust $\mathrm{pH}$ with ammonium hydroxide. Make up to $1 \mathrm{~L}$ with water. Store at $4{ }^{\circ} \mathrm{C}$.

5. Passivation solution: $1 \mathrm{mM}$ L-lysine. Add about $40 \mathrm{~mL}$ of current buffer to a $50 \mathrm{~mL}$ plastic flacon. Weigh $0.00731 \mathrm{~g} \mathrm{~L}$-lysine, and transfer to the flacon. Dissolve the powder, and add current buffer to a final volume of $50 \mathrm{~mL}$. Leave one aliquot at $4{ }^{\circ} \mathrm{C}$ for current use, and store the remaining aliquots at $-20{ }^{\circ} \mathrm{C}$. 
6. Regeneration solution: $0.1 \mathrm{M}$ glycine- $\mathrm{HCl}, \mathrm{pH} 2.0$. Add about $35 \mathrm{~mL}$ water to a $50 \mathrm{~mL}$ graduated cylinder or a glass beaker. Weigh $0.37535 \mathrm{~g}$ glycine, and transfer to the cylinder. Add water to a volume of $40 \mathrm{~mL}$. Mix and adjust $\mathrm{pH}$ with $\mathrm{HCl}$ (see Note 1). Add water to a final volume of $50 \mathrm{~mL}$ with water. Store at $4{ }^{\circ} \mathrm{C}$.

\subsection{Equipment}

1. UV-ozonolyzer.

2. Laboratory rocker.

3. Light table.

4. Petri dish.

5. Polystyrene box.

6. Box filled with ice.

7. Empty squeeze bottle.

8. $50 \mathrm{~mm}$ diameter glass beakers.

9. Plastic flacons $50 \mathrm{~mL}$.

10. Aluminum foil.

11. Parafilm.

12. Lens wipes (no-dust optic wipes).

13. Plastic tweezers.

\subsection{Instrument}

2.5.1. SPR

1. SPR imaging (SPRi) experiments should be performed using an 
SPRi-Plex imager (HORIBA Scientific, France) equipped with $660 \mathrm{~nm}$ light-emitting diode (LED) and charge-coupled device (CCD) camera or imager with similar specifications. Data acquisition and instrument control should be performed via SPRiView P4.1.0, and quantitative analysis of the experimental data should be done with the software SPRi-Analysis 1.2.1 or equivalent.

2. SPRi glass prism.

3. Gold-covered glass slides: thickness $\times$ length $\times$ width $=0.5 \mathrm{~mm} \times 28 \mathrm{~mm} \times 12 \mathrm{~mm}$, chromium bonding layer 1-2 nm, gold layer $50 \mathrm{~nm}$, roughness: maxi $7 \AA$ (see Note 2).

\subsubsection{MALDI-TOF Mass Spectrometry}

1. MALDI-TOF experiments should be performed using an Autoflex Speed MALDI-TOF/TOF MS instrument or equivalent. This instrument is equipped with a SmartBeam II ${ }^{\mathrm{TM}}$ laser (modified $\mathrm{Nd}$ :YAG laser) pulsed with $1 \mathrm{kHz}$ frequency. Mass spectra acquisition and instrument control should be performed via FlexControl 3.4. Mass spectra should be processed using FlexAnalysis software (version 3.3.80.0) or equivalent.

2. TLC adapter MALDI target plate (i.e., target plate for MALDI imaging with fixations).

3. Customized transparent plastic film, used as a mask figuring the array pattern to guide the manual spot deposition (see Note 3 ).

4. Matrix solution: 0.05 M 2-(4-Hydroxyphenylazo)-benzoic acid (HABA) in acetonitrile/water $50 \% / 50 \%(\mathrm{v} / \mathrm{v}), 0.2 \%$ trifluoroacetic acid (TFA). Weigh $12.1 \mathrm{mg}$ of HABA in a plastic vial. Add $1 \mathrm{~mL}$ of acetonitrile/water 50/50\% (v/v), 0.2\% TFA. Dissolve matrix and mix solution thoroughly to ensure that matrix solution is homogeneous.

\section{Methods}


Preparation steps described in Subheadings 3.1-3.3 are for the preparation of two biochips (see Note 4).

\subsection{Gold Surface Cleaning}

Prior to use, the gold surface of the glass slides is systematically cleaned by ozonolysis. Glass slide handling should be performed exclusively with plastic tweezers.

1. Rinse the gold-covered glass slides with copious amounts of acetone, and dry with airflow using an empty squeeze bottle nozzle (see Note 5).

2. Rinse glass slides with copious amounts of ethanol absolute, and dry again as in step 1.

3. Drop glass slides off (gold side up) in the UV-ozonolyzer for $30 \mathrm{~min}$.

\subsection{PEG Self-Assembled Monolayer}

1. Dissolve aliquot ( $3.5 \mu \mathrm{L} \sim 4 \mathrm{mg})$ of PEG in $3.48 \mathrm{~mL}$ of ethanol absolute to obtain a $2.5 \mathrm{mM}$ PEG solution, and mix it thoroughly. Transfer solution into a $50 \mathrm{~mL}$ beaker. Tightly cover the beaker with parafilm and aluminum foil (see Note 6).

2. Immerse the UV-ozonolysis cleaned biochips (gold side up) one by one in the PEG solution. Take care not to overlay them.

3. Cover the beaker with several layers of parafilm and aluminum foil. Put the covered beaker inside a polystyrene box, and close the lid.

4. Place the polystyrene box on the laboratory rocker, and rock at $50 \mathrm{rpm}$ for $6 \mathrm{~h}$.

5. Stop the rocker, and take out the beaker with the biochips. Take the biochips out one by one, rinse them with ethanol absolute, and immerse them into another beaker filled with ethanol absolute. 
6. Repeat step 3, and leave the box on the laboratory rocker and rock at $50 \mathrm{rpm}$ for $5 \mathrm{~min}$.

7. Stop the rocker, and take out the beaker with the biochips. Take the biochips out, and rinse them again with ethanol absolute. Handling the biochips one by one, place them (gold side up) on a paper towel, and dry them using airflow from an empty squeeze bottle. AQ4

8. Transfer biochips to a Petri dish and close the lid. Cover the Petri dish with aluminum foil.

\subsection{PEG Activation}

1. Mix $727 \mu \mathrm{L}$ of $715 \mathrm{mM}$ DCC in DMSO with $727 \mu \mathrm{L}$ of $660 \mathrm{mM}$ NHS in DMSO and $727 \mu \mathrm{L}$ of $660 \mathrm{mM}$ 4-pyrrolidinopyridine in DMSO (or dissolve $55.2 \mathrm{mg}$ of NHS, $106 \mathrm{mg}$ of DCC, and $7 \mathrm{mg}$ of 4-pyrrolidinopyridine in $2.17 \mathrm{~mL}$ of DMSO; see Note 7) in a beaker.

2. Take the biochips out of the Petri dish, and immerse them one by one in the activation solution mixture prepared in step 1.

3. Cover the beaker with several layers of aluminum foil. Put the covered beaker inside the polystyrene box, and close the lid.

4. Place the polystyrene box on the laboratory rocker, and rock at $50 \mathrm{rpm}$ for $16 \mathrm{~h}$.

5. Stop the rocker, and take out the beaker with the biochips. Take biochips out, rinse them with DMSO, and immerse them into another beaker filled with DMSO. AQ5

6. Repeat step 3, and leave on the laboratory rocker rocking at $50 \mathrm{rpm}$ for $5 \mathrm{~min}$.

7. Stop the rocker, and take out the beaker with the biochips. Take the biochips out, rinse them with water, and immerse them into another 
beaker filled with water.

8. Repeat step 3, and leave on the laboratory rocker rocking at $50 \mathrm{rpm}$ for $5 \mathrm{~min}$.

9. Stop the rocker, and take out the beaker with the biochips. Take the biochips out one by one, and rinse them with water again.

10. Place the biochips (gold side up) on a paper towel, and dry them using airflow from an empty squeeze bottle.

11. Transfer the biochips into separate empty, labelled flacons. Tightly close the lids, and wrap the flacons with aluminum foil. Store at $4{ }^{\circ} \mathrm{C}$ (see Note 8).

\subsection{Antibody Grafting}

1. Take the flacon with the biochip from the fridge, and leave it for $1 \mathrm{~h}$ at room temperature before immobilization of antibodies. Do not remove the aluminum foil before using the biochip.

2. Prepare $6 \mu \mathrm{M}$ antibody solution containing 5\% glycerol: To each $5 \mu \mathrm{L}$ aliquot of $1 \mathrm{mg} / \mathrm{mL}(\sim 6.67 \mu \mathrm{M})$ solution of each antibody, add $0.5 \mu \mathrm{L}$ of $55 \%$ glycerol. Mix thoroughly and keep on ice during the spotting of the antibodies. Afterward, store at $4{ }^{\circ} \mathrm{C}$ and mix thoroughly prior to next usage.

3. Indicate the positions to be arrayed on the transparent plastic film. Then place this plastic film on the light table. Place the biochip over the transparent plastic film in order to see where to spot.

4. Spot manually $0.2 \mu \mathrm{L}$ droplets of anti- $\beta$-lactoglobulin and control anti-ovalbumin antibody solutions (prepared in step 2) onto the surface of the biochip in an array format according to the spot locations indicated on the transparent plastic film placed on the light table.

5. Put the biochip inside the Petri dish with a piece of wet paper towel inside (to ensure humidity), close the lid, and wrap it tightly with 
parafilm and cover with aluminum foil.

6. Leave the biochips for immobilization at $4{ }^{\circ} \mathrm{C}$ for $16 \mathrm{~h}$ before the SPRi experiment. If time-saving is a priority, immobilization time can be reduced (see Note 9).

\subsection{Biochip - SPRi Prism Assembly}

\section{AQ6}

1. Clean the SPRi glass prism by spraying it with ethanol absolute and wiping with lens wipes. Thoroughly dry the prism, and insert it in the prism holder of the SPRi device.

2. Depose $1 \mu \mathrm{L}$ (or less, see Note 10) of the refractive index matching oil on the surface of the prism, and gently slide the biochip over the prism. Ensure no air bubbles remain between the glass slide and the prism (see Note 11).

\subsection{Passivation of the Biochip Surface}

The free reactive NHS groups remaining after antibody grafting are passivated by reaction with L-lysine.

1. Insert the prism holder containing the prism and mounted biochip inside the SPRi device, and fix it.

2. Inject $150 \mu \mathrm{L}$ of $1 \mathrm{mM}$ L-lysine in current buffer followed by injection of $150 \mu \mathrm{L}$ of the regeneration solution (see Note 12 for injection details). Repeat this injection sequence three times.

\subsection{SPRi Experiment}

1. Prepare a $100 \mu \mathrm{g} / \mathrm{mL}$ stock solution of $\beta$-lactoglobulin $(\sim 5.45 \mu \mathrm{M})$ : weigh $0.2 \mathrm{mg}$ of $\beta$-lactoglobulin in a plastic vial (i.e., $2 \mathrm{~mL}$ plastic tube), and add $2 \mathrm{~mL}$ of SPRi current buffer. Mix well to dissolve the powder completely. Store at $4{ }^{\circ} \mathrm{C}$ up to 1 week and mix thoroughly prior to next use.

2. Dilute the $5.45 \mu \mathrm{M} \beta$-lactoglobulin stock solution in the SPRi 
current buffer to obtain the tenfold analyte dilution series 545 and $54.5 \mathrm{nM} \beta$-lactoglobulin (see Note 13). Store at $4{ }^{\circ} \mathrm{C}$ up to 1 week, and mix thoroughly prior to next use.

3. Define the spots as regions of interest (ROIs) in the SPRi analysis software. Set the flow rate to obtain a laminar flow in the flow cell $(50 \mu \mathrm{L} / \mathrm{min}$ when using the SPRi-Plex device (see Note 14 for experimental setup details). Wait for the SPRi baseline stabilization.

4. Inject $150 \mu \mathrm{L}$ of $54.5 \mathrm{pM}(1 \mu \mathrm{g} / \mathrm{mL}) \beta$-lactoglobulin solution, and monitor the receptor-ligand interactions (see Note $\mathbf{1 2}$ for the injection details).

5. At the end of the dissociation phase, inject $150 \mu \mathrm{L}$ of the regeneration solution.

6. Repeat steps $\mathbf{4}$ and $\mathbf{5}$ for successive increasing concentrations of $\beta$-lactoglobulin (see Note 15).

7. For the biochip dedicated to further MALDI analysis, the last injection of $\beta$-lactoglobulin should not be followed by the regeneration step in order to keep the captured ligand on the biochip.

8. Stop the SPRi experiment, and remove the prism holder from the SPRi. Gently remove the biochip from the prism, and dry it thoroughly with airflow (see Note 16).

9. Clean the SPRi prism by spraying it with ethanol absolute and wiping with lens wipes. Thoroughly dry the prism, and store it.

\subsection{MALDI-TOF MS Experiment}

1. Depose $0.11 \mu \mathrm{L}$ of the MALDI matrix solution on each receptor spot as well as on several receptor-free locations serving as controls immediately after the biochip drying (see Note 17). The spot positions are identified after the SPRi experiment by using the transparent plastic film (figuring spot location) placed over a light 
table.

2. Allow the matrix to crystalize (dry) completely. Put the biochip in a labelled flacon, tightly close it, and store it at $4{ }^{\circ} \mathrm{C}$ until MALDITOF MS experiment (see Note 18).

3. Insert the biochip into the MALDI target plate, and introduce it into the mass spectrometer source.

4. Record mass spectra using the following set of parameters: linear positive mode $450 \mathrm{~ns}$ delay; source ion 1 (IS1) voltage, $19.5 \mathrm{kV}$; source ion 2 (IS2) voltage, $17.65 \mathrm{kV}$; lens voltage, $6.5 \mathrm{kV}$. Mass range: 5000-100,000 $\mathrm{Da}$. The laser intensity should be set to just above the ionization threshold. Laser shots should be accumulated over each spot to obtain a better signal-to-noise ratio (see Note 19). AQ7

5. Eject the MALDI plate (target), and recover the biochip. Put the biochip in a labelled flacon, and store it for possible further analysis at room temperature in the absence of light.

\section{Notes}

1. Concentrated $\mathrm{HCl}(12 \mathrm{M})$ can be used at first to narrow the gap from the starting $\mathrm{pH}$ to the desired $\mathrm{pH}$. From then on, it would be better to use less concentrated $\mathrm{HCl}$ (e.g., 6 and $1 \mathrm{M}$ ) to avoid a sudden drop in $\mathrm{pH}$ beyond the target $\mathrm{pH}$ value.

2. At first glance, it is difficult to identify the gold side. We recommend using glass slides with a mark, for instance, a bevelled corner in order to facilitate orientation and routine manipulations.

3. A light table and a customized plastic film with marked spot localizations are required for manual spotting and matrix deposition. Alternatively, a commercial spotter can be used; in this case, refer to the settings of the manufacturer. Keep the spot deposition scheme, indicating the position of immobilized molecules - it will be required for the definition of SPRi spots and 
matrix deposition as well.

4. Given the duration of the activation procedure $(\sim 20 \mathrm{~h})$, it is convenient to functionalize two biochips at the same time. For that purpose, all materials (including the beaker size) were adapted for preparation of two biochips. Materials, such as beaker size and chemicals, should be readjusted for different numbers of biochips.

5. Ensure that you are handling the biochips with the gold side up all the time and that the gold-covered surface does not come into contact with any objects (wipes, beaker walls, etc.) in order to avoid any contamination or damage. Take care not to damage or scratch the gold coverage during manipulations, especially with the tweezers.

6. Parafilm is used to prevent evaporation, while aluminum foil (and, eventually, the polystyrene box) ensures protection against any photochemical reaction of the thiol function of PEG.

7. We find it most convenient to prepare separate stock solutions by accurate weighing of dry DCC, NHS, and 4-pyrrolidinopyridine in distinct plastic vials (i.e., $2 \mathrm{~mL}$ plastic tubes). Right before the activation step, dry products should be dissolved in the proper amount of DMSO directly in the vial. We advise to use a vortex and/or ultrasound bath (short pulses) to ensure that reagents are completely dissolved. Alternatively, DCC, NHS, and 4-pyrrolidinopyridine solutions might be prepared a few hours in advance and stored in separate tightly covered glass beakers at room temperature $\left(25^{\circ} \mathrm{C}\right)$ in the absence of light.

8. Activated SPRi biochips can be stored up to 1 month at $4{ }^{\circ} \mathrm{C}$, protected from humidity and in the absence of light.

9. 2 hours is the minimum required time. If time-saving is not a priority, immobilization time can be extended for better results.

10. The volume of the refractive index matching oil required for the efficient adhesion of the biochip to the prism depends strongly on the viscosity of the oil and the surface to be covered, so it should 
be adapted for each particular case. The volume should be sufficient to completely fill the space without air bubbles between the prism and the biochip, but not in excess to avoid oil bleed at the prism sides.

11. We suggest deposing the oil in a line shape, rather than droplet, and start sliding the biochip over the surface. We have found that relatively viscous oil deposition near the short side of the prism and slow sliding along the surface result in optimal coverage without air bubbles.

AQ8

12. Each injection consists of two phases of distinct lengths: an association phase $(\sim 5 \mathrm{~min}$ at a $50 \mu \mathrm{L} / \mathrm{min}$ flow rate) and a dissociation phase $(\sim 15-30 \mathrm{~min}$ at a $50 \mu \mathrm{L} / \mathrm{min}$ flow rate), successively. The length of each phase depends on the SPRi system design and receptor-ligand couple used; thus, it should be adapted for each particular case.

13. For protein serial dilution, we recommend the use of plastic tubes with volumes slightly superior to the syringe volume used for protein loading into the flow cell. For example, the use of $2 \mathrm{~mL}$ plastic tubes combined with $1 \mathrm{~mL}$ syringe will allow the highest recovery of the solution from the bottom of the vial.

14. We are using an SPRi system with a hexagonal-shaped flow cell. It was maintained at $25{ }^{\circ} \mathrm{C}$, and the flow rate was fixed at $50 \mu \mathrm{L} / \mathrm{min}$ across all experiments. The flow rate should be adapted depending on the SPR system used: it should be neither fast, nor mass transport limited, to permit efficient monitoring of molecular interactions.

15. We have found that additional injection of current buffer prior to the next analyte injection maintains the cleanliness of the loop and ensures that the obtained SPRi response is produced by the analyte interactions with the immobilized receptors only.

16. At this stage, it is possible to include a direct on-chip trypsin digestion step in order to ascertain the identification of the 
affinity-captured antigen protein. It is performed by directly dropping the trypsin protease on each spot of the biochip followed by MALDI-TOF MS identification of the resulting peptides according to $[18,21]$.

17. Control MALDI matrix spots should be located both inside and outside the SPRi flow cell area in order to control the efficiency of the surface chemistry passivation.

18. We strongly recommend performing MS analysis immediately after matrix deposition and drying. Nevertheless, storage at $4{ }^{\circ} \mathrm{C}$ in the dark for up to 1 week is also acceptable. Beyond this period, the efficiency (sensitivity) of MS analysis is seriously decreased, likely due to protein degradation.

19. We suggest accumulating hundreds of shots per spot to obtain a clear mass spectrum.

\section{Acknowledgments}

Authors are indebted to Dr. D. Lebeau for access to the MALDI-TOF/TOF MS instrument (Den-Service d'Etude du Comportement des Radionucléides, CEA, Paris-Saclay University, France); A. H. acknowledges fellowships from Université d'Evry-Paris Saclay and Région Ile-de France (Dim Analytics).

\section{References}

1. Karlsson R, Michaelsson A, Mattsson L (1991) Kinetic analysis of monoclonal antibody-antigen interactions with a new biosensor based analytical system. J Immunol Methods 145(229-240):229-240

2. Homola J (2003) Present and future of surface plasmon resonance biosensors. Anal Bioanal Chem 377(3):528-539

3. Wassaf D et al (2006) High-throughput affinity ranking of antibodies using surface plasmon resonance microarrays. Anal Biochem 351(2):241-253 
4. Homola J (2008) Surface plasmon resonance sensors for detection of chemical and biological species. Chem Rev 108(2):462-493

5. Nogues C, Leh H, Langendorf CG, Law RHP, Buckle AM, Buckle M (2010) Characterisation of peptide microarrays for studying antibodyantigen binding using surface plasmon resonance imagery. PLoS One $5(8): 1-7$

6. Nogues C, Leh H, Lautru J, Delelis O, Buckle M (2012) Efficient antifouling surface for quantitative surface plasmon resonance based biosensor analysis. PLoS One 7(9):e44287

7. Nedelkov D, Nelson RW (2001) Analysis of native proteins from biological fluids by biomolecular interaction analysis mass spectrometry (BIA/MS): exploring the limit of detection, identification of nonspecific binding and detection of multi-protein complexes. Biosens Bioelectron 16(9-12):1071-1078

8. Gilligan JJ, Schuck P, Yergey AL (2002) Mass spectrometry after capture and small-volume elution of analyte from a surface plasmon resonance biosensor. Anal Chem 74(9):2041-2047

9. Boireau W, Rouleau A, Lucchi G, Ducoroy P (2009) Revisited BIA-MS combination: entire 'on-a-chip' processing leading to the proteins identification at low femtomole to sub-femtomole levels. Biosens Bioelectron 24(5):1121-1127

10. Xue J, Bai Y, Liu H (2019) Hybrid methods of surface plasmon resonance coupled to mass spectrometry for biomolecular interaction analysis. Anal Bioanal Chem 411(17):3721-3729

11. Krone JR, Nelson RW, Dogruel D, Williams P, Granzow R (1997) BIA/MS: interfacing biomolecular interaction analysis with mass spectrometry. Anal Biochem 244(1):124-132

12. Jansson Ö, Larsericsdotter H, Zhukov A, Areskoug D, Oscarsson S, Buijs J (2006) Optimizing the surface plasmon resonance/mass spectrometry interface for functional proteomics applications: how to 
avoid and utilize nonspecific adsorption. Proteomics 6:2355-2364

13. Bouffartigues E, Leh H, Anger-Leroy M, Rimsky S, Buckle M (2007) Rapid coupling of Surface Plasmon Resonance (SPR and SPRi) and ProteinChip ${ }^{\mathrm{TM}}$ based mass spectrometry for the identification of proteins in nucleoprotein interactions. Nucleic Acids Res 35(6):e39

14. Stigter ECA, de Jong GJ, van Bennekom WP (2009) Development of an on-line SPR-digestion-nanoLC-MS/MS system for the quantification and identification of interferon- $\gamma$ in plasma. Biosensor Bioelectron 24(7):2184-2190

15. Zhang $Y$ et al (2015) Interface for online coupling of surface plasmon resonance to direct analysis in real time mass spectrometry. Anal Chem 87(13):6505-6509

16. Joshi S, Zuilhof H, van Beek TA, Nielen MWF (2017) Biochip spray: simplified coupling of surface plasmon resonance biosensing and mass spectrometry. Anal Chem 89(3):1427-1432

17. Nedelkov D (2007) Development of surface plasmon resonance mass spectrometry array platform. Anal Chem 79(15):5987-5990

18. Bellon S et al (2009) Hyphenation of surface plasmon resonance imaging to matrix-assisted laser desorption ionization mass spectrometry by on-chip mass spectrometry and tandem mass spectrometry analysis. Anal Chem 81(18):7695-7702

19. Remy-Martin F et al (2012) Automated cancer marker characterization in human plasma using SUrface PLASMON Resonance in Array combined with Mass Spectrometry (SUPRA-MS). Procedia Chem 6:11-19

20. Stigter ECA, de Jong GJ, van Bennekom WP (2013) Coupling surfaceplasmon resonance and mass spectrometry to quantify and to identify ligands. TrAC-Trends Anal Chem 45:107-120

21. Musso J et al (2015) Biomarkers probed in saliva by surface plasmon 
resonance imaging coupled to matrix-assisted laser desorption/ionization mass spectrometry in array format. Anal Bioanal Chem 407(5):1285-1294

22. Przybylski C et al (2019) Surface plasmon resonance imaging coupled to on-chip mass spectrometry: a new tool to probe protein-GAG interactions. Anal Bioanal Chem (in press). https://doi.org/10.1007/s00 216-019-02267-2 AQ9 